\title{
Off-label prescriptions in intensive care unit: the Chinese experience
}

This article was published in the following Dove Press journal:

Therapeutics and Clinical Risk Management

\author{
Lin Liu \\ Hong-Yu Yang \\ Yan Lou \\ Jing Miao \\ Xiao-Yang Lu \\ Qing-Wei Zhao \\ Rong-Rong Wang \\ Sai-Ping Jiang* \\ Xing-Guo Zhang* \\ Department of Pharmacy, The \\ First Affiliated Hospital, College \\ of Medicine, Zhejiang University, \\ Hangzhou, People's Republic of China \\ *These authors contributed equally \\ to this work
}

Background and purpose: Off-label prescriptions for critically ill patients pose several ethical and legal dilemmas for intensive care unit (ICU) clinicians. Yet, few data are available on the prevalence of this practice in critical care environment in China. This nationwide survey was performed to evaluate the conditions of off-label prescriptions in ICU within China.

Methods: The survey was performed at the scene of the national ICU conferences in 2016. ICU clinicians attending the congress from 23 provinces across the country were invited. The features of the clinician's off-label prescription practice were investigated and analyzed. Results: A total of 1,318 ICU clinicians completed the anonymous questionnaire. Of these, $76.2 \%$ prescribed off-label in clinical practice. A significant difference $(p<0.005)$ was observed between the ICU clinicians with different years of working experience and professional levels, respectively. For $69.2 \%$ of the ICU clinicians, the proportion of off-label prescriptions did not exceed $10 \%$, while for fewer prescribers $(2.9 \%)$, the proportion exceeded $25 \%$. The main reasons for off-label prescriptions were life-threatening or terminal medical condition without other substitutes (48.3\%), new treatments with strong scientific evidence (38.1\%), and limited indications of drug labels (22.7\%). Of the ICU clinicians surveyed, $87.5 \%$ worried about causing medical disputes, and $26.5 \%$ encountered medical disputes caused by off-label prescriptions. The risk of medical disputes was positively associated with the proportion of off-label prescriptions ( $p=0.009$ ). Among the ICU clinicians, 92.5\% expected the national policy for off-label prescriptions in future. Gastrointestinal and respiratory drug classes were noted to have the highest prevalence of off-label use.

Conclusion: Off-label prescriptions have been commonly practiced by ICU clinicians in China. A concerted effort should be made to develop a practical and explicit guidance for off-label prescriptions.

Keywords: off-label prescriptions, intensive care unit, questionnaire, Chinese hospitals

\section{Introduction}

Off-label prescription is the practice of prescribing drugs for an unapproved indication or age group, dose, or regimen of administration. ${ }^{1}$ In China, an unregistered or unlicensed medicine is a medicine or dosage form of a medicine that has not been approved or evaluated by the China Food and Drug Administration (CFDA) for specific indications which were supported by efficacy and safety information offered by manufacturers, including indication, age group, dose, and regimen of administration. ${ }^{2}$ This limited review process narrows down the scope of approving labeling, and therefore, leads to prevalent off-label prescriptions. ${ }^{3}$

Off-label prescription is also widespread in other countries across the world. For example, in USA, it is indicated that the proportion of off-label prescription is up to $21 \%$ in the ambulatory care setting. ${ }^{4}$ More commonly, literature from some restricted
Correspondence: Sai-Ping Jiang

The First Affiliated Hospital, College of Medicine, Zhejiang University, 79 Qingchun Road, Hangzhou 310003, People's Republic of China

Tel +8657I 87236675

Email j5I45@I26.com
Therapeutics and Clinical Risk Management 2018:14 195-202

(c) (1) (8) ( 2018 Liu et al. This work is published and licensed by Dove Medical Press Limited. The full terms of this license are avalable at htrps://mww.dovepress.com/terms.php

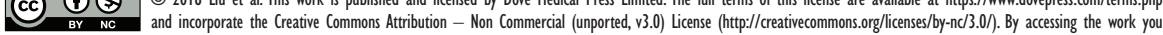
hereby accept the Terms. Non-commercial uses of the work are permitted without any further permission from Dove Medical Press Limited, provided the work is properly attributed. For peminsion for commercial use of this work, please see paragraphs 4.2 and 5 of our Terms (https://www.dovepress. com/terms.php). 
clinical populations (eg, pediatrics and oncology) reported that as much as $70 \%$ of drug use was off-label. ${ }^{3,5-8}$ The intensive care unit (ICU) has also been a setting where the prevalence of off-label prescription is high. Critically ill patients present a complex array of challenges that may limit the quality and quantity of evidence required for an approved indication from drug labeling. ${ }^{9}$ Critical illness afflicts multiple organs simultaneously; therefore, it is unable to provide encompassing and holistic therapies from the researches dedicated to singular organ systems. Due to the shortage of funds to promote innovative research and the lack of active oversight to guarantee the efficacy and safety of medication treatment, ICU clinicians may routinely practice therapeutic regimen including off-label drugs that may be ineffective and even harmful. ${ }^{10}$

However, the controversy about off-label prescriptions has never been stopped during the past decade. On one hand, off-label prescriptions are important to medical practice. They promote innovation in routine care, allow development of novel practices based on growing evidence, and provide available treatments for life-threatening or terminal medical condition. Due to the lack of tailored therapeutics for the critically ill patients, off-label prescriptions are used for bridging the gap between available treatments and optimal therapeutic outcomes. ${ }^{10}$ On the other hand, off-label prescriptions have not been formally and rigorously evaluated for labeled indications, associated with drug-related problems, such as medical disputes, costs, and ethics, and a potentially increased risk of adverse drug events. ${ }^{11-13}$ One of the examples for the use of off-label prescriptions in ICU is that vasopressin is adopted for the therapy of septic shock, which is recommended restraint in use for clinical equipoise until it has been tested in multicenter studies. ${ }^{14}$

To our knowledge, there are only two studies that have documented the situation of off-label prescriptions in the adult critical care setting. A French study provides an evaluation from a single ICU. The proportion of off-label prescriptions was $26.5 \%$. The main reasons for off-label prescriptions were unapproved indication (66\%), dosing schedule (27\%), and method of administration (17\%). ${ }^{10}$ In a USA study, $36.2 \%$ of medication orders were off-label. Most of the off-label prescriptions $(89.1 \%)$ were initiated after patient admission to the ICU. Moreover, $48.3 \%$ of the off-label prescriptions had grade $\mathrm{C}$ or no evidence. ${ }^{10}$ Thus far, there are no data in the literature about this practice in Chinese hospitals.

The off-label prescriptions for critically ill patients lead to some ethical and legal issues for ICU clinicians, especially in the constructs of optimal therapy, evidence-based medicine, and drug safety. ${ }^{10}$ Although there are some rationales for off-label drug use in ICU, few data or literature on the prevalence of off-label prescriptions and correlative factors in the critical care environment in China are available. Therefore, this nationwide questionnaire study was performed to collect comprehensive and detailed information on the use of offlabel drugs among critical care patients, and the results of the questionnaire were analyzed for evaluating the conditions of off-label prescriptions in ICU within China.

\section{Methods \\ Study design and participants}

This questionnaire study was designed by The First Affiliated Hospital, College of Medicine, Zhejiang University, and directed by Department of Pharmacy of the hospital. The ethics committee of The First Affiliated Hospital, College of Medicine, Zhejiang University, approved this study. The questionnaire included questions on participants' characteristics, such as working experience, professional levels, academic qualifications, and hospital levels; 13 questions were developed with reference to a comprehensive literature review about off-label prescriptions. A preliminary test was performed to balance the coherence and the burden of the survey. This survey was performed at the scene of the national ICU conferences in 2016, and the ICU clinicians attending the congress from 23 provinces across the country were invited. Each of them received the paper questionnaire and answered anonymously. Before the participants started to answer the questions, we informed them about the significance and use of the questionnaire, and completion of the questionnaire was deemed to be providing informed consent.

\section{Data collection}

All questionnaires were collected at the scene of the conferences. Demographic data were recorded for each participant. Furthermore, participants were defined as prescribers or nonprescribers of off-label drugs according to their answers to the first question. A specific question tree followed for prescribers of off-label drugs, whereas non-prescribers of off-label drugs accomplished the questionnaire after answering the first question. The survey questions are shown in Table 1. Answers of each questionnaire were recorded for further analyses.

\section{Statistical analyses}

Descriptive statistics were calculated to analyze the characteristics of the participants and the answer patterns to each question. Chi-square test was performed to compare the features of clinicians within different groups (prescriber or non-prescriber of off-label drugs). Spearman's rank 
Table I Survey questions and answers

This questionnaire study was performed to collect comprehensive and detailed information on use of off-label drug among critical care patients, and to evaluate the conditions of off-label prescriptions in ICU within China. All results of this questionnaire would be analyzed and used for publication. Completion of the questionnaire is deemed to be providing informed consent.

Clinicians who participated in this survey; $n=1,318$

Q I Did you prescribe off-label in clinical practice? $\quad$ I) Yes (76.2\%); 2) No (23.1\%); 3) Others (0.6\%)

(Off-label prescriptions is the practice of prescribing

drugs for an unapproved indication or age group, dose, or regimen of administration.)

If Yes, please give examples of off-label prescriptions you prescribed.

Indications ( ); Drug ( ); Dosage ( ); Routes of administration ( ); Others ( )

Clinicians who prescribed off-label; $n=I, 004$ (76.2\%)

Q 2 Did you check the use against the defined indications for the drug in the approved labeling when you prescribe drugs?

Q 3 What percentage of your prescription would be considered off-label?

Q 4 What was the most common reason for prescribing off-label drugs? (multiple choices)

Q 5 What was your primary source of information about off-label drug use? (multiple choices)

Q 6 What was the main kind of literature as a basis when prescribing off-label drugs? (multiple choices)

I) All (33.7\%); 2) The majority (49.6\%); 3) Examined occasionally (14.2\%); 4) Rarely (I.7\%); 5) Never (0.2\%)

I) $1 \%-10 \%(69.2 \%)$; 2 ) II\%-25\% (I8.4\%); 3) $26 \%-50 \%(2.9 \%)$; 4$)>50 \%(0.76)$; 5) Unclear $(8.74 \%)$

I) Limited indications of drug labels (22.7\%); 2) New treatments with strong scientific evidence (38.1\%); 3) Life-threatening or terminal medical condition without other substitutes (48.3\%); 4) Recommended by colleagues or clinical experience (16.7\%); 5) Requirements from patients (4.2\%); 6) Unfamiliar with drug instructions (1.2\%); 7) Other (3.1\%)

I) Medical literature (65.0\%); 2) Pharmacists (15.3\%); 3) Colleagues (19.4\%);

4) Medical conferences (35.0\%); 5) Pharmaceutical manufacturers (10.9\%);

6) Textbooks (7.3\%); 7) Other (0.9\%)

I) International authoritative guidelines (62.5\%); 2) Foreign meta-analysis (22.3\%);

3) Foreign randomized controlled trials (I7.7\%); 4) Other foreign literatures (II.2\%); 5) Domestic authoritative guidelines (42.7\%); 6) Chinese experts consensus (31.5\%); 7) Other Chinese literatures (5.4\%); 8) Other (2.0\%)

Q 7 Did you inform patients when you prescribe off-label drugs?

I) Never (9.6\%); 2) Unless it's necessary (26.5\%); 3) The majority of patients (26.9\%); 4) All of patients (35.6\%)

Q 8 Would the off-label prescriptions be a matter of record?

I) Never (8.1\%); 2) Recorded according to patients and drugs (38.1\%); 3) Recorded after awareness of off-label prescriptions (46.5\%); 4) Blank (7.3\%)

Q 9 Did you obtain informed consents from the patients before prescribing off-label?

I) Never (16.9\%); 2) Sometimes (30.0\%); 3) Often (32.1\%); 4) Always (20.4\%); 5) Blank (0.6\%)

Q 10 Did you worry about encountering off-label I) Yes (87.5\%); 2) No (II.2\%); 3) Blank (0.6\%)

prescriptions related medical disputes?

Q II Have you ever encountered any medical disputes caused by off-label prescriptions?

Q I2 In your opinion, what are the most important measures to minimize off-label prescriptions related risks? (multiple choices)

Q I3 Did you expect the national policy or regulations for off-label prescriptions?

correlation coefficient was calculated to find the association between the characteristics of the clinicians and answers to a question or between answers to two different questions. A two-tailed $p<0.05$ was considered significant.

\section{Results}

\section{Characteristics of ICU clinicians}

The characteristics of ICU clinicians who participated in this study are shown in Table 2. A total of 1663 ICU clinicians were asked to take part in the questionnaire survey, and of these, 1318 (79.3\%) completed the anonymous questionnaire, of which $984(74.6 \%)$ were from class 3-A hospitals, 205 (15.6\%) from class 3-B hospitals, 78 (5.9\%) from class 2-A hospitals, and three from class 2-B hospitals. (In China, the hospitals are divided into three classes according to their bed numbers. There are more than 500 beds, 101-500 beds, and less than 100 beds in class 3 , class 2 , and class 1 hospitals, respectively. Class 2 and class 3 hospitals are divided into 
Table 2 Characteristics of ICU clinicians participated in this survey

\begin{tabular}{ll}
\hline Characteristics & $\begin{array}{l}\text { No of } \\
\text { clinicians (\%) }\end{array}$ \\
\hline Working experience & $393(29.8)$ \\
I-5 years & $403(30.6)$ \\
$6-10$ years & $190(14.4)$ \\
II-I5 years & $286(21.7)$ \\
$>$ I5 years & $46(3.5)$ \\
Blank & \\
Professional title & $159(12.1)$ \\
Chief clinician & $330(25.0)$ \\
Deputy chief clinician & $439(33.3)$ \\
Attending doctor & $310(23.5)$ \\
Resident doctor & $80(6.1)$ \\
Blank & \\
Academic qualification & $142(10.8)$ \\
Medical doctor & $539(40.9)$ \\
Master & $563(42.7)$ \\
Bachelor & $74(5.6)$ \\
Blank & \\
Hospital level & $984(74.6)$ \\
Class 3-A & $205(15.6)$ \\
Class 3-B & $78(5.9)$ \\
Class 2-A & $3(0.2)$ \\
Class 2-B & $49(3.7)$ \\
Blank &
\end{tabular}

Abbreviation: ICU, intensive care unit.

$\mathrm{A}, \mathrm{B}$, and $\mathrm{C}$ levels according to the differences in technical level, medical condition, management level, and research capacity. Here, class 3-A is the most authoritative hospital). In particular, 159 were chief clinicians (12.1\%), 330 were deputy chief clinicians (25.0\%), 439 were attending doctors (33.3\%), and 310 were resident doctors (23.5\%), with a mean $10.2 \pm 6.7$ years of working experience. The percentages of the clinicians with various academic qualifications were as follows: medical doctor, $10.8 \%$; master, $40.9 \%$; and bachelor, $42.7 \%$.

\section{Prevalence of off-label prescriptions in ICU}

In the questionnaire, the concept of off-label prescriptions was clearly explained: an off-label prescription is said to be when a drug is used in a way that is different from what is described in the approved labeling. In order to confirm that the clinicians participated understood the concept, examples of off-label prescriptions, including indications, dosages, routes of administration, and others, were required to be filled in the questionnaires. Only after each example in the questionnaire was checked, the questionnaire was accepted. Table 1 lists the raw responses to the survey questions. Overall, $76.2 \%$ of the ICU clinicians prescribed off-label drugs in clinical practice. After comparing their features, a significant difference $(p<0.005)$ was observed between them with different years of working experience and professional levels, respectively, while no significant difference was found between prescribers with various academic qualifications $(p=0.198)$ and hospital levels $(p=0.017)$ (Figure 1). In detail, ICU clinicians with working experience exceeding 6 years were associated with more off-label prescriptions (from $78.0 \%$ to $89.3 \%$ ) than those working for $1-5$ years $(55.5 \%)$. Clinicians with bachelor's degree prescribed off-label drugs less frequently than those with doctor's degree $(74.3 \%$ vs $85.7 \%$ ). Off-label prescriptions were significantly less prescribed by resident doctors $(58.2 \%)$ than clinicians at higher professional levels (from $76.8 \%$ to $92.1 \%$ ). Furthermore, among prescribers of off-label drugs, the proportion of offlabel prescriptions did not exceed $10 \%$ for $69.2 \%$ of the ICU clinicians, while for fewer prescribers $(2.9 \%)$, the proportion exceeded $25 \%$. However, $13.4 \%$ of the prescribers were not aware of the extent of their off-label prescriptions.

\section{Reasons and behavior patterns for ICU off-label prescriptions}

From the survey, the main reasons for off-label prescriptions were found to be life-threatening or terminal medical condition without other substitutes (48.3\%), new treatments with strong scientific evidence (38.1\%), and limited indications of drug labels (22.7\%) (Figure 2). When prescribing off-label drugs, $65.0 \%$ of the ICU clinicians chose medical literature as reference information, and international authoritative guidelines were the most common literature referred (62.5\%), which was followed by domestic authoritative guideline (42.7\%) (Figure 3).

Since the informed consent is a fundamental right for patients in disease diagnosis and treatment, about $70 \%$ of the ICU clinicians informed the majority of patients or all patients. However, $26.5 \%$ of the ICU clinicians preferred not to disclose unless it was necessary, and $9.6 \%$ never disclosed. About $84 \%$ of the ICU clinicians indicated the off-label prescriptions should be a matter of record, yet only about $52 \%$ obtained written informed consent from the patients.

\section{Risks of prescribing off-label drugs}

As off-label prescriptions are not covered by law in China, $87.5 \%$ of the ICU clinicians worried about causing medical disputes, and $26.5 \%$ encountered medical disputes caused by off-label prescriptions. Spearman's rank correlation showed the risk of medical disputes was positively associated with the proportion of off-label prescriptions $(p=0.001)$; in contrast, 

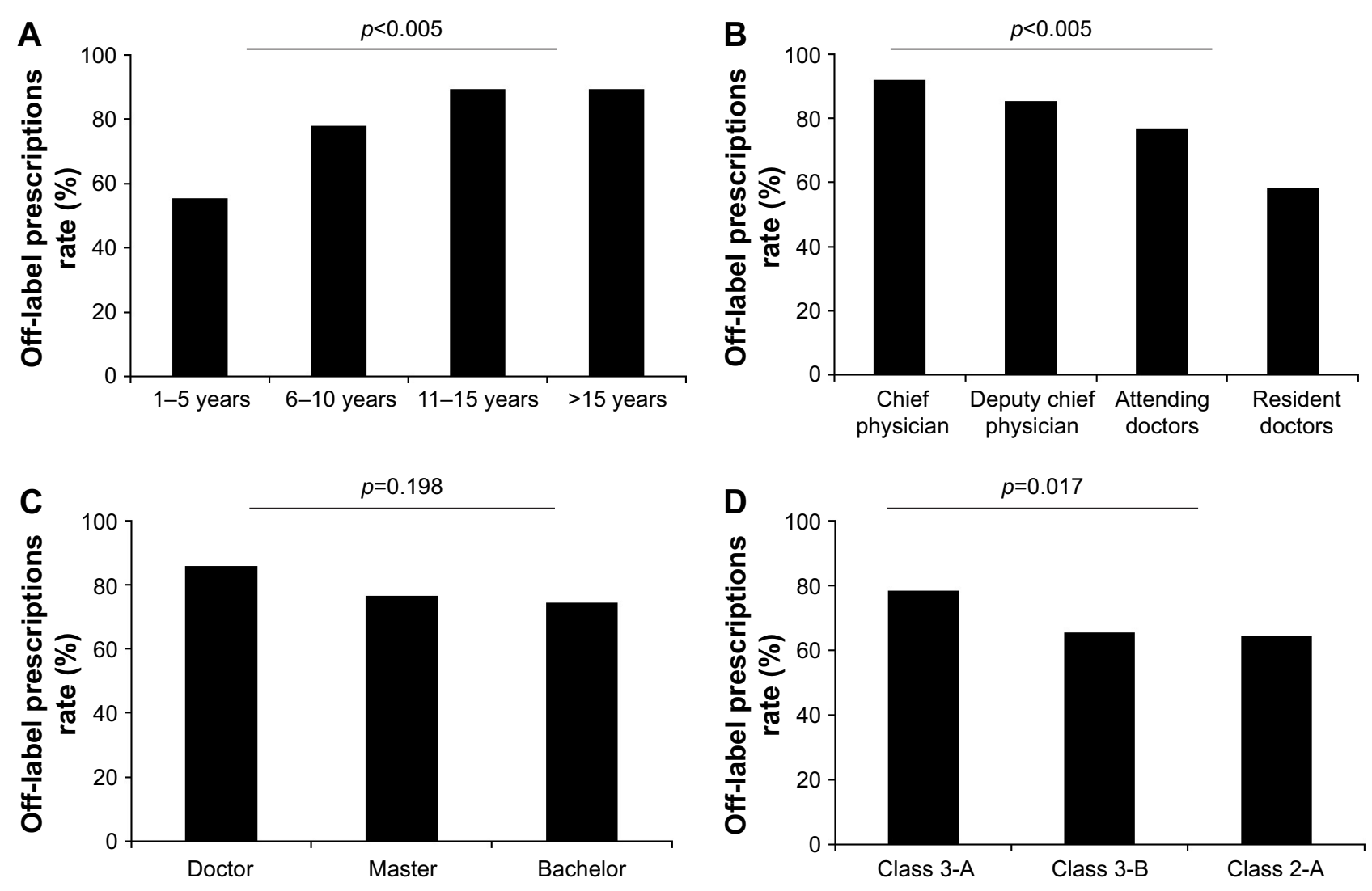

Figure I Characteristics of off-label prescribers in intensive care unit.

Notes: (A) Years of working experience. (B) Professional levels. (C) Academic qualifications. (D) Hospital levels.

the extent of disclosure about off-label prescriptions to patients was not associated ( $p=0.167$ ) (Table 3 ).

To minimize the risks related to off-label prescriptions, obtaining written consent from the patients $(40.6 \%)$ and following national policy or regulations for off-label prescriptions (30.4\%) were supposed to be the most important measures. As a result, $92.5 \%$ of the ICU clinicians expected the national policy or regulations for off-label prescriptions in future.

\section{Categories of off-label prescriptions}

Table 4 shows the frequently prescribed drugs and classification of medication use in an unlicensed manner in ICU. The most common category of off-label prescriptions was dosage (45.7\%), and the next was indication (28.8\%). When analyzing the class of agents, gastrointestinal and respiratory drug classes were noted to have the highest prevalence of off-label use ( $40.3 \%$ and $32.6 \%$, respectively).

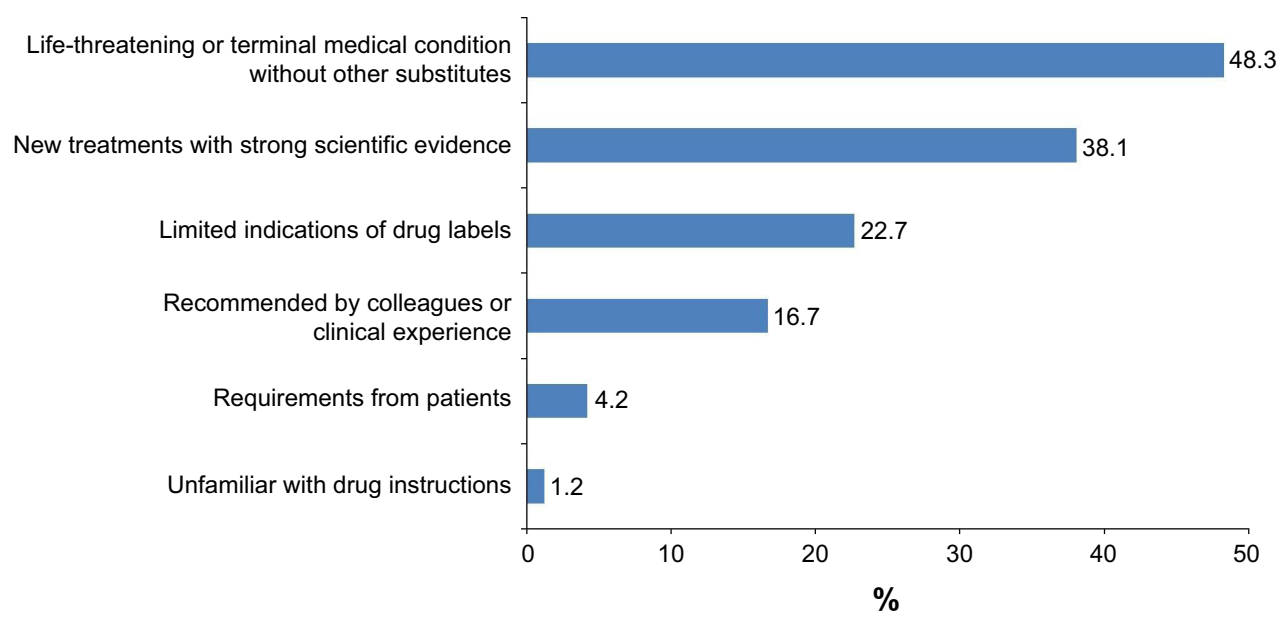

Figure $\mathbf{2}$ The most common reason for prescribing an off-label drug. 


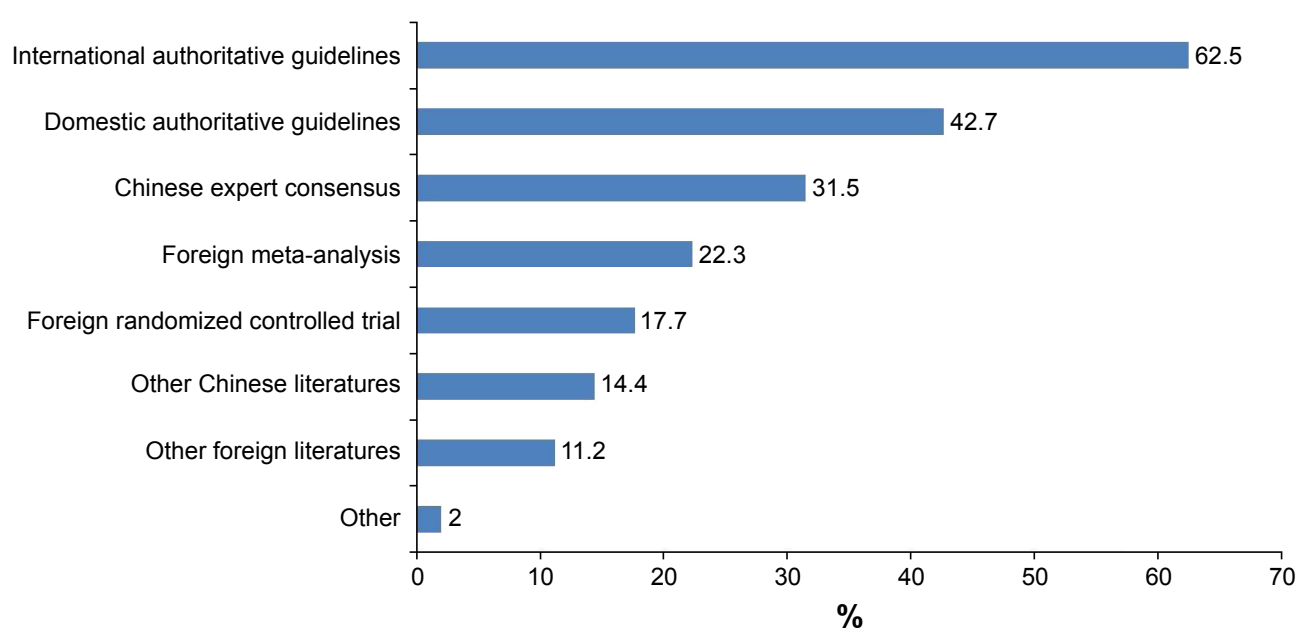

Figure 3 The main kind of literature as a basis for off-label prescriptions.

\section{Discussion}

Off-label prescribing is not covered by the law in China. It may sometimes be clinically appropriate, but is related to several ethical, clinical, and safety problems. ${ }^{15}$ So far, there has been no explicit national regulation to help clinicians assess appropriateness of off-label prescribing. A study which analyzed the adverse drug reactions (ADRs) in China recently found that off-label prescription was the common cause. ${ }^{16}$ Another study showed that about $77 \%$ of medications involved in error reports were used off-label, ${ }^{17}$ indicating that the safety of off-label prescriptions may lack visibility. However, few reports had systematically evaluated the magnitude of off-label prescription in China, especially from the view of clinicians. This study for the first time revealed the characteristics, the reasons, the behavior patterns, and the risks of off-label prescriptions in ICU within the Chinese health care system.

In this survey, $76.2 \%$ of the ICU clinicians prescribed off-label drug, which confirms a high degree of off-label use

Table 3 Correlation analysis of the risks of medical disputes caused by off-label prescriptions

\begin{tabular}{|c|c|c|c|c|}
\hline \multirow{2}{*}{\multicolumn{2}{|c|}{$\begin{array}{l}\text { Encountered } \\
\text { medical } \\
\text { disputes }\end{array}$}} & \multicolumn{3}{|c|}{ Proportion of off-label prescriptions } \\
\hline & & $1 \%-10 \%$ & $11 \%-25 \%$ & $>\mathbf{2 5 \%}$ \\
\hline \multirow{5}{*}{$\begin{array}{l}\text { Yes } \\
\text { No } \\
p=0.001\end{array}$} & & 174 & 67 & 15 \\
\hline & & 520 & 118 & 22 \\
\hline & & & & \\
\hline & Disc & sure extent of o & -label prescriptions & \\
\hline & All & The majority & Unless necessary & Never \\
\hline Yes & 89 & 69 & 81 & 27 \\
\hline No & 268 & 201 & 185 & 69 \\
\hline$p=0.167$ & & & & \\
\hline
\end{tabular}

among ICU patients. Years of working experience and professional levels were found to be related to the frequency of off-label prescription. Although off-label prescription among ICU patients in China was not as prevalent as in other clinical departments or other counties, ${ }^{4,10,18-20}$ as the proportion of offlabel prescription for most of the prescribers was no more than $10 \%$, a worrisome problem is that $10.2 \%$ of prescribers were not aware of the extent of their off-label prescription, suggesting medicines used off-label may be ignored by some ICU clinicians. Accordingly, it is important to improve the training of the clinicians on the subject, in order to increase the information on the risks inherent in using off-label drugs, so as to increase the awareness of the prescribers.

Table 4 Off-label prescriptions by functional class

\begin{tabular}{|c|c|c|}
\hline $\begin{array}{l}\text { Functional } \\
\text { class }\end{array}$ & $\begin{array}{l}\text { Typical off-label } \\
\text { drugs }\end{array}$ & $\begin{array}{l}\text { Classification of off-label } \\
\text { prescription }\end{array}$ \\
\hline Gastrointestinal & $\begin{array}{l}\text { Proton pump } \\
\text { inhibitors, ulinastatin }\end{array}$ & $\begin{array}{l}\text { Off-label prescription in } \\
\text { relation to indication, dosage }\end{array}$ \\
\hline $\begin{array}{l}\text { Respiratory } \\
\text { system }\end{array}$ & $\begin{array}{l}\text { Ambroxol injection, } \\
\text { budesonide }\end{array}$ & $\begin{array}{l}\text { Off-label prescription in } \\
\text { relation to dosage, route of } \\
\text { administration, and indication }\end{array}$ \\
\hline Anti-infectives & $\begin{array}{l}\text { Tigecycline, } \\
\text { cefoperazone } \\
\text { sulbactam }\end{array}$ & $\begin{array}{l}\text { Off-label prescription } \\
\text { in relation to dosage, dose } \\
\text { of frequency, route of } \\
\text { administration, indication, } \\
\text { age, etc }\end{array}$ \\
\hline $\begin{array}{l}\text { Vitamins, trace } \\
\text { elements, and } \\
\text { nutriceuticals }\end{array}$ & $\begin{array}{l}\text { Injection of potassium } \\
\text { chloride, magnesium } \\
\text { sulfate }\end{array}$ & $\begin{array}{l}\text { Off-label prescription } \\
\text { in relation to dosage }\end{array}$ \\
\hline Hematology & $\begin{array}{l}\text { Alprostadil injection, } \\
\text { intravenous human, } \\
\text { immunoglobulin, } \\
\text { aplastic anemia drugs, } \\
\text { human serum, albumin }\end{array}$ & $\begin{array}{l}\text { Off-label prescription } \\
\text { in relation to indication }\end{array}$ \\
\hline
\end{tabular}


Given the lack of availability of appropriate labeled drugs, in many clinicians' opinions (48.2\%), off-label use remains the only therapeutic alternative; therefore, it accounts for a rather high percentage of drug therapies in ICU. Of the prescribers surveyed, $65.0 \%$ made off-label use-related decisions based on medical literature. However, there is significant disparity between what may be considered suitable or unsuitable off-label drug uses. A number of off-label drug uses are recognized as standard of medical treatment and even endorsed by professional organizations (eg, ranitidine for stress ulcer prophylaxis), while others are extrapolated from studies conducted in populations not from ICU or lacking consistent evidence to support the use (eg, intensive insulin therapy). ${ }^{21-24}$ Most clinicians preferred to choose the high-quality guidelines which were regarded as including recommendations intended to optimize patient care. ${ }^{15}$ Consequently, more and stronger body of evidences are needed comparing the clinical significance of off-label medication use with those encountered when drugs are used consistently with indications approved by the CFDA.

Since off-label prescription is inevitable, it is worth pondering the clinical implications for widespread off-label drug use. First, the threshold to discontinue therapies should be considered when off-label treatments are ineffective. A previous study enrolling 150 million off-label prescriptions in USA indicated that $73 \%$ had little or even no scientific evidence. ${ }^{4}$ Moreover, several long-term uses of off-label drugs have been proved to be ineffective or even harmful when evaluated appropriately. Most clinicians perceive off-label use as proper and consider it is likely to be more a benefit than a bane. However, irrational increase of costs for the health care system can be caused by the misuse of off-label drugs, and a legal risk for the prescribing clinician could be represented if patients have an undesirable or a bad outcome from the therapy.

In addition, due to the lack of high-quality randomized controlled trials, pharmacologic and toxicological mechanisms of actions or researches utilizing surrogate markers can be used to extrapolate risk-benefit ratios. Off-label prescriptions represent a delicate balance between the prerogatives of clinicians to make professional judgment during therapy and the regulatory objective of protecting patients from ineffective or unsafe medicines. Even if an off-label indication is approved by the national drug administration, clinicians are required to take responsibility for its use. ${ }^{25}$ Consequently, off-label drugs should be prescribed only when the benefits outweigh risks, and clinicians must obtain informed consent from the patients in any case, including information on the therapeutic regimen, alternatives, expected benefits, and potential risks. Obviously, in this survey, clinicians appeared to have a low level of concern about issues surrounding informed consent, yet more than $90 \%$ of the clinicians expected the laws for off-label uses, reflecting the urgency to address the legality and appropriateness of off-label prescriptions in China. Also, guidance on appropriate processes for obtaining informed consent is urgently needed, as an explicit process for obtaining patient consent will contribute to better inform patients about the relationship between benefits and risks associated with innovative treatment using off-label medication.

Several limitations exist in this study, which must be considered. First, it was limited to a relatively small clinician population that not covered all of the medical institutions. Our data from this survey might not capture the practice entirely and might underrepresent off-label prescriptions. Second, the results were based on opinions from clinicians rather than records of prescriptions, which, if considered, might decrease the prevalence of off-label prescriptions, as clinicians may ignore prescriptions outside the dosage, routes of administration, or patient population. However, there is no national database to record the prescriptions behaviors in China, and it is difficult to obtain records from different and independent systems in various hospitals. Third, a further problem associated with off-label prescriptions is the occurrence of ADRs, which was not included in our survey. Some studies found a very high proportion of ADRs in the pediatric population which is associated with off-label prescriptions or that children who are administered off-label drugs have an increased risk of developing ADRs. ${ }^{26}$

\section{Conclusion}

Our findings indicate that off-label prescriptions have been commonly practiced by ICU clinicians among Chinese hospitals, accompanied with the legal risk of medical disputes and a low level of concern about informed consent for most ICU clinicians. A concerted effort should be made to develop explicit and practical approaches to guide clinicians, policymakers, and funders of health care in systematically appraising the appropriateness of off-label prescriptions.

\section{Acknowledgments}

The authors sincerely thank Jim Jorgenson and Pranish Kantesaria for their excellent assistance in conceiving and designing the questionnaire. This study was supported by the National Natural Science Foundation of China (Nos 81503256 and 81402862). 


\section{Author contributions}

All authors contributed to this work. Lin Liu acquired, analyzed, and interpreted the data from questionnaires and drafted the manuscript. Hong-Yu Yang participated in designing the questionnaire and interpreted the data. Yan Lou participated in designing the questionnaire. Jing Miao performed the statistical analysis and revised the manuscript. Rong-Rong Wang performed the statistical analysis and drafted the manuscript. Xiao-Yang Lu analyzed and interpreted the data from questionnaires. Qing-Wei Zhao performed the statistical analysis and revised the manuscript. Sai-Ping Jiang conceived of the study, and participated in its design and coordination and helped to draft the manuscript. Xing-Guo Zhang contributed substantially to the study design, the data analysis, and the writing of the manuscript. All authors read and approved the final manuscript. All authors contributed toward data analysis, drafting and revising the paper and agree to be accountable for all aspects of the work.

\section{Disclosure}

The authors report no conflicts of interest in this work.

\section{References}

1. Wittich CM, Burkle CM, Lanier WL. Ten common questions (and their answers) about off-label drug use. Mayo Clin Proc. 2012;87(10): 982-990.

2. Zheng Z, Xu F. Chinese pharmacists propose patient consent for unlabeled use of medications. J Manag Care Pharm. 2010;16(8):640.

3. Choonara I, Conroy S. Unlicensed and off-label drug use in children: implications for safety. Drug Saf. 2002;25(1):1-5.

4. Radley DC, Finkelstein SN, Stafford RS. Off-label prescribing among office-based clinicians. Arch Intern Med. 2006;166(9):1021-1026.

5. Brosgart CL, Mitchell T, Charlebois E, et al. Off-label drug use in human immunodeficiency virus disease. J Acquir Immune Defic Syndr Hum Retrovirol. 1996;12(1):56-62.

6. Krause E, Malorgio S, Kuhn A, Schmid C, Baumann M, Surbek D. Off-label use of misoprostol for labor induction: a nation-wide survey in Switzerland. Eur J Obstet Gynecol Reprod Biol. 2011;159(2):324-328.

7. Baldwin DS, Tiwari N, Gordon R. Sense and sensibility when prescribing 'off-label' to psychiatric patients. Curr Pharm Des. 2015;21(23): 3276-3279

8. Mortenson LE. The off-label debate: a threat to the future of cancer care. Cancer Investig. 1991;9(5):597-599.

9. Latif A, Rawat N, Pustavoitau A, Pronovost PJ, Pham JC. National study on the distribution, causes, and consequences of voluntarily reported medication errors between the ICU and non-ICU settings. Crit Care Med. 2013;41(2):389-398.

Therapeutics and Clinical Risk Management

\section{Publish your work in this journal}

Therapeutics and Clinical Risk Management is an international, peerreviewed journal of clinical therapeutics and risk management, focusing on concise rapid reporting of clinical studies in all therapeutic areas, outcomes, safety, and programs for the effective, safe, and sustained use of medicines. This journal is indexed on PubMed Central, CAS,
10. Lat I, Micek S, Janzen J, Cohen H, Olsen K, Haas C. Off-label medication use in adult critical care patients. J Crit Care. 2011;26(1):89-94.

11. Good CB, Gellad WF. Off-label drug use and adverse drug events: turning up the heat on off-label prescribing. JAMA Intern Med. 2016; 176(1):63-64.

12. McCarthy M. Off-label drug use is associated with raised risk of adverse events, study finds. BMJ. 2015;351:h5861.

13. Eguale T, Buckeridge DL, Verma A, et al. Association of off-label drug use and adverse drug events in an adult population. JAMA Intern Med. 2016;176(1):55-63.

14. Russell JA. Vasopressin in septic shock: clinical equipoise mandates a time for restraint. Crit Care Med. 2003;31(11):2707-2709.

15. Berdkan S, Rabbaa L, Hajj A, et al. Comparative assessment of offlabel and unlicensed drug prescriptions in children: FDA versus ANSM guidelines. Clin Ther. 2016;38(8):1833-1844.

16. Gao P, Zhang CL, Zeng FD, et al. Pharmacovigilance in China: issues of concern identified through an analysis of the Chinese Adverse Drug Reaction Information Bulletin 2001 to 2014. J Clin Pharm Ther. Epub 2015 Aug 20.

17. Rinke ML, Bundy DG, Shore AD, Colantuoni E, Morlock LL, Miller MR. Pediatric antidepressant medication errors in a national error reporting database. J Dev Behav Pediatr. 2010;31(2):129-136.

18. Lindell-Osuagwu L, Korhonen MJ, Saano S, Helin-Tanninen M, Naaranlahti T, Kokki H. Off-label and unlicensed drug prescribing in three paediatric wards in Finland and review of the international literature. J Clin Pharm Ther. 2009;34(3):277-287.

19. Morales-Carpi C, Estañ L, Rubio E, Lurbe E, Morales-Olivas FJ. Drug utilization and off-label drug use among Spanish emergency room paediatric patients. Eur J Clin Pharmacol. 2010;66(3):315-320.

20. Lerose R, Musto P, Aieta M, Papa C, Tartarone A. Off-label use of anti-cancer drugs between clinical practice and research: the Italian experience. Eur J Clin Pharmacol. 2012;68(5):505-512.

21. Barletta JF, Bruno JJ, Buckley MS, Cook DJ. Stress ulcer prophylaxis. Crit Care Med. 2016;44(7):1395-1405.

22. Cook D, Guyatt G, Marshall J, et al. A comparison of sucralfate and ranitidine for the prevention of upper gastrointestinal bleeding in patients requiring mechanical ventilation. Canadian critical care trials group. N Engl J Med. 1998;338(12):791-797.

23. NICE-SUGAR Study Investigators; Finfer S, Chittock DR, Su SY, et al. Intensive versus conventional glucose control in critically ill patients. N Engl J Med. 2009;360(13):1283-1297.

24. Yang CP, Veltri MA, Anton B, Yaster M, Berkowitz ID. Food and Drug Administration approval for medications used in the pediatric intensive care unit: a continuing conundrum. Pediatr Crit Care Med. 2011;12(5):e195-e199.

25. Levêque D. Off-label use of anticancer drugs. Lancet Oncol. 2008; 9(11):1102-1107.

26. Magalhães J, Rodrigues AT, Roque F, Figueiras A, Falcão A, Herdeiro MT. Use of off-label and unlicenced drugs in hospitalised paediatric patients: a systematic review. Eur J Clin Pharmacol. 2015; 71(1):1-13.

\section{Dovepress}

EMBase, Scopus and the Elsevier Bibliographic databases. The manuscript management system is completely online and includes a very quick and fair peer-review system, which is all easy to use. Visit http://www.dovepress.com/testimonials.php to read real quotes from published authors. 